\title{
Conjuntura atual: instigando a busca de rumos e o que fazer
}

\author{
Current conjuncture: instigating the search of directions and what \\ to do
}

Nelson Rodrigues dos Santos ${ }^{1}$

Neste artigo de opinião, objetivamos contribuir ao conhecimento e participação política na atual crise: de possível esgotamento da governabilidade e dos projetos de governo pós-ditadura. Na transição para uma nova etapa, poderá constar no seu horizonte um nível mais democratizado e civilizado das representações da sociedade no quadro partidário, no processo eleitoral, e nos poderes Executivo e Legislativo, com efetivos controles democráticos dos poderes delegados pela sociedade civil. Para maior consistência nessa busca de rumos e o que fazer, julgamos imprescindível relembrar cinco etapas anteriores geradoras da atual conjuntura, retomando-as resumidamente com análises conjunturais incompletas ou controversas, mas de consideração inabdicável em nossas buscas. Deixamos para o final breve alusão à política pública de saúde, que, como as demais, decorre da mencionada governabilidade e dos projetos de governo pós-ditadura.

\section{Período 1930/1963 - coexistência entre oligarquias e dependência dos EUA com esforços desenvolvimentistas e distributivistas, rumo a um projeto de nação}

1 Universidade Estadual de Campinas (Unicamp) - Campinas (SP), Brasil. Instituto de Direito Sanitário Aplicado (Idisa) Campinas (SP), Brasil. nelsonrs@fcm.unicamp.br
Nesse período observou-se uma continuidade dos esforços pela industrialização 'tardia', beneficiada pela substituição de importações dos países centrais envolvidos na II Guerra Mundial. Criou-se a indústria de base: Companhia Siderúrgica Nacional, Vale do Rio Doce, Petrobrás, hidroelétricas, rodovias e outras, com grande expansão da indústria e comércio satélite da metalurgia, construção civil e inúmeros outros ramos. O Produto Interno Bruto (PIB) teve marcante crescimento com consequente mobilização social nos grandes e médios centros urbanos, que redundou em políticas distributivistas puxadas pela Consolidação das Leis do Trabalho (CLT) e pela Lei Orgânica da Previdência Social (Lops). A partir de 1955, desenvolve-se como órgão do Ministério da Educação o Instituto Superior de Estudos Brasileiros (Iseb) que integrou forte movimento intelectual desenvolvimentista com influência no governo federal. Ao final desse período, o Poder Legislativo, refletindo historicamente e majoritariamente as oligarquias rural e urbana com entranhado viés fisiológico/patrimonialista/venal no trato do orçamento público, foi convivendo e sendo pressionado gradativamente pelos crescentes movimentos sindicais e sociais e levado a compor com os avanços acima referidos. 
Apesar de histórica e majoritariamente fisiológico, o Legislativo nacional, com intermitência crescente, reagia como 'caixa de ressonância' da sociedade de forma pluripartidária às pressões desenvolvimentistas; e no seu interior, as tendências progressistas, mesmo minoritárias, ganhavam fôlego e capacidade de influência e negociação. Nos últimos anos desse período, já atuava no Congresso Nacional a Frente Parlamentar Nacionalista, pluripartidária, com influência crescente. $\mathrm{O}$ debate social pressionava os poderes Executivo e Legislativo pelas 'reformas de base': agrária (com extensão da CLT ao trabalho rural), urbana, industrial, tributária e outras, além da ampliação do comércio externo aos demais continentes. Não por acaso, foi realizada, em 1963, a histórica III Conferência Nacional de Saúde. Ainda que tardiamente em relação às revoluções industriais na Europa e EUA, os paradigmas do Estado republicano avançavam entre o ranço secular escravagista, feudal e patrimonialista do Estado brasileiro. Alinhavam-se aos países em desenvolvimento que buscavam, nesse período, uma 'terceira via' de projeto de nação e desenvolvimento no meio da aguda bipolarização mundial. O paradigma das reformas de base caminhava na direção do Estado de Bem-Estar Social (Ebes) já consolidado nos países europeus e outros. Em 1964, deu-se o golpe militar iniciando a ditadura civil-militar.

\section{Período 1964/1984 - ditadura com anulação da participação democrática no projeto de nação}

No campo político: fechamento do Legislativo nacional e posterior reabertura com cassações de mandatos parlamentares, prisões, tortura e extermínio. O poder Executivo, por meio de Atos Institucionais e Decretos-Lei, assume com exclusividade toda a legislação estratégica e cria dois partidos: Arena, situacionista majoritário (soma ampliada dos anteriores partidos conservadores fisiológicos), que lhe assegura a legislação restante; e o de oposição Movimento Democrático Brasileiro (MDB) (soma reduzida do trabalhismo anterior e outras tendências progressistas).

Com a nova política econômica, o País caminha para uma das maiores concentrações de renda no mundo, com pauperização rural e nas pequenas cidades, que leva à explosiva migração para as periferias das cidades médias e grandes, com inevitável elevação das tensões sociais. Nos 20 anos de ditadura, o Estado, à guisa do 'seu' projeto de nação, priorizou obras faraônicas valendo-se ilicitamente de recursos previdenciários (transamazônica, ponte Rio-Niterói, usina Itaipu, usina nuclear, indústria bélica e outras), o que potencializou o desenvolvimento de grandes empreiteiras que se apropriaram de tecnologia nessa área, empresas satélites e grande capital. Destaque: nesses 20 anos, foram ceifadas quatro gerações da renovação democrática no Legislativo e Executivo nacional (duas gerações etárias) com profunda interrupção e distorção na cultura política democrática e eleitoral da sociedade, referente à legitimidade das representações políticas e ao debate democrático do projeto de nação. Foi imposto um projeto de poder bancado pelos militares. Nesses 20 anos, duas gerações de lideranças políticas e de formuladores de políticas e projetos nacionais democráticos e desenvolvimentistas em todos os segmentos sociais foram reduzidas a 'restos' sem impacto. Ainda assim, ao final dos anos 1970, crescem nos desvãos da ditadura atividades políticas em entidades sociais, de trabalhadores, artísticas, eclesiais, intelectuais, científicas, estudantis e de bairros, que vão se ampliando às classes médias e empresariado sob a bandeira unitária das 'Liberdades Democráticas'. 


\section{Período dos anos 1980 - maior mobilização democrática da história da sociedade brasileira}

Somaram-se às 'Liberdades Democráticas': as 'Diretas Já' e a 'Democratização do Estado' como lemas e bandeiras de grandes e crescentes mobilizações, já nas ruas à luz do dia, apontando para o fim da ditadura, que além dos desastrosos legados sociais, econômicos e políticos, deixaram uma inflação de difícil controle. Na sequência, a delegação ao Congresso Nacional de poderes constituintes, sob intensa mobilização, pressão e participação das entidades da sociedade nos debates constituintes que seguiram. O Título da Ordem Social avançou para um dos mais civilizados do mundo em direitos sociais, e o orçamento da seguridade social para assegurá-los. Não houve fôlego político unitário para os debates constitucionais avançarem mais na direção do projeto de nação com as reformas estruturais do Estado: agrária, urbana, tributária, política/eleitoral, industrial e outras, mas as bases estavam dadas para as etapas imediatas pós-Constituição. Esse período teve o significado para nossa sociedade da retomada do amplo debate por um projeto de nação no rumo de um Ebes brasileiro.

Nesse mesmo período dos anos 1980, em escala mundial e precipitada pela grande crise do petróleo dos anos 1970, configurava-se, nos países do 'capitalismo central', a estratégia global neoliberal formulada e pactuada por mais de uma década por representações do grande capital e seus 'intelectuais orgânicos' selecionados e convocados. Foi o 'Consenso de Washington' que dispôs sobre a financeirização dos orçamentos públicos que: a) impôs autonomia aos bancos centrais para fixar no mercado financeiro os juros e demais serviços da dívida pública, cujos montantes, por definição, não constam como objeto de austeridade governamental; b) definiu as despesas públicas primárias (investimento na infraestrutura do desenvolvimento, direitos sociais etc.) como perdulárias e objeto de austeridade pelos governos; c) definiu o deficit primário quando as despesas primárias excedem o que resta à receita após o pagamento dos juros e demais serviços da dívida; d) estabelece o significado e papéis do capitalismo central e do periférico/ dependente na atual globalização; e) assume que a maior ameaça contemporânea ao desenvolvimento é o Ebes e o keynesianismo; e f) prega a reforma do Estado com enxugamento das estruturas e orçamentos sociais, substituindo-os por programas focais compensatórios público-privados de baixo custo. A concentração do capital, riqueza e poder cresceram em poucas décadas em níveis jamais imaginados. Em 2016, a respeitada Oxfam confirmou a previsão, com base na pesquisa de Piketty (2013), de que os $1 \%$ mais ricos do mundo passariam a deter $50 \%$ das riquezas do planeta. Deve ser destacado que, a essa concentração de riqueza e renda, correspondem geração e concentração de poder e estratégias do seu exercício com eficácia nunca antes alcançada nos países do capitalismo central e nos periféricos.

\section{Período 1990-2002}

Voltando ao Brasil, os governos criaram expectativas na sociedade apresentando diversos imaginários e medidas de controle da hiperinflação herdada, o que acabou ocorrendo em 1993/1994 com o Plano Real e despertando esperanças na retomada do desenvolvimento e de amplo debate das reformas estruturais do Estado e na aplicação dos preceitos constitucionais. A população, esperançosa com o retorno à democracia liberal e ao avanço constitucional, vai gradativamente se frustrando com a implementação das seguintes diretrizes estratégicas pouco ou nada debatidas com a sociedade e mesmo com o Legislativo: 1) reajuste do salário mínimo abaixo da inflação; 2) vultosos estímulos financeiros públicos para a expansão da rede bancária privada e venda barata dos bancos públicos aos bancos privados; 3) exorbitante 
elevação nos juros da dívida pública e na venda dos títulos da dívida; 4) câmbio favorável às importações e desfavorável às exportações; 5) abertura comercial e financeira ao mercado externo; 6) desinvestimento público e privado na industrialização; 7) compressão dos gastos públicos sociais e elevação dos gastos públicos com os serviços da dívida pública (os encargos da dívida pública saltaram de $18,7 \%$ do Orçamento Geral da União em 1995 para 44\% em 2002); 8) privatização das empresas estatais; e 9) atração da estrutura sindical para realizar e pleitear acesso aos direitos à saúde e educação nos serviços privados de mercado fortemente subsidiados com recursos públicos.

A hiperinflação, enorme e perverso sorvedouro da riqueza produzida pela grande maioria da população, é substituída pateticamente em um 'passe de mágica' pela altíssima dívida e juros públicos entre os maiores do mundo, um sorvedouro maior da economia da sociedade, porém 'moderno', planejado e aparentemente ético e perene. A implementação das diretrizes estratégicas acima citadas ao longo desse período não só frustrou a desejada desconcentração da renda e inclusão social como intensificou a concentração e gerou a emergência dos rentistas da dívida pública, novo segmento social hegemônico que absorve quase metade do Orçamento Geral da União, de influência decisiva na política econômica, e que é liderado pelos grandes bancos privados e agencias de investimento e do mercado financeiro. Levaram à degradação do trabalho urbano e rural; simultaneamente, à desindustrialização e desnacionalização, assim como inibiram e distorceram estruturalmente as políticas públicas para os direitos sociais.

A política econômica industrial retrocedeu à exportação primária e importação de máquinas e manufaturas de maior valor agregado, sucateando as promissoras cadeias produtivas de derivados de grãos, da química fina, informática, telecomunicação, máquinas e outras. Na dobrada do século, o tradicional 'chão de fábrica' de gerações de industriais passava a 'linhas de montagem' e, por fim, a grandes lojas de vendas. Simultaneamente, a política econômico-financeira passou a atrair a aplicação dos lucros empresariais ao mercado financeiro e de capitais, esvaziando seu reinvestimento na produção. Em 2005, $75 \%$ dos juros da dívida pública estavam apropriados por 20 mil famílias de rentistas (pouco mais de um centésimo da população) revelando o poder concentrador de renda do sistema financeiro. Tornou-se indisfarçável o caráter do Banco Central e dos ministérios da Fazenda, da Casa Civil e do PlanejamentoOrçamento-Gestão, de ministérios estratégicos de Estado que induzem os eixos da gestão nos demais ministérios, com forte indução nas políticas públicas reais ou implícitas. Afastou-se da expectativa pós-constitucional da implementação de projeto de nação com reformas estruturais desenvolvimentistas do Estado com amplo debate social. Optou-se por um projeto de poder e governo viabilizado por intelectuais tecnocratas economistas e financistas e, por isso, antipopular.

Por fim, ressaltamos uma característica dos governos nesse período, talvez histórica, especialmente a partir de 1993, que foi o modo de construção pelo poder Executivo do apoio do poder Legislativo - Congresso Nacional à implementação das referidas nove diretrizes estratégicas antipopulares, com exceção do controle da inflação. Essas diretrizes passam a conviver e a interagir com o histórico fisiologismo, patrimonialismo e venalidade na relação do Legislativo com o Executivo. Para implementar legalmente essas diretrizes impopulares na democracia liberal, o poder Executivo assume para si a prerrogativa da formulação da legislação estratégica por meio de crescente número de Medidas Provisórias (MPs) e Projetos de Emendas Constitucionais (PECs) por ele enviadas ao Congresso Nacional, cuja aprovação só poderia se efetivar com a garantia de ampla e fiel maioria nas casas legislativas.

Como assegurar essa maioria? Três pontos 
de partida: a) prática histórica do enriquecimento ilícito e financiamento por grandes empresas de campanhas eleitorais para cadeiras no poder Legislativo (principalmente de reeleições); b) prática histórica de lideranças e dirigentes parlamentares garantirem aprovação de projetos do Executivo mediante a contratação em certos cargos executivos, de nomes por eles indicados; e c) prática histórica de superfaturamento por grandes empresas e empreiteiras contratadas pelo Executivo para fornecimento de materiais e grandes obras. Cada uma dessas três práticas ilícitas à custa dos recursos públicos vinha se desenvolvendo e crescendo no seu campo próprio de interesses e negócios sem grandes obstáculos. $\mathrm{O}$ fato novo foi o Executivo, agora na Democracia liberal, e não mais na ditadura, induzir no Legislativo uma retração na sua prerrogativa constitucional do exercício da legislação estratégica e do controle do Executivo no cumprimento das Leis. O conjunto dos fatos que vieram a público foi revelando que o Executivo foi articulando a sistematização da triangulação das três práticas históricas existentes, potencializando sua eficácia, o que lhe assegurou as condições legais necessárias para implementação das referidas nove diretrizes estratégicas. Essa triangulação sobrepôs-se ao desenvolvimento de pactos sociais mais civilizados remetidos pelo debate constitucional com vistas a amplo debate de projeto de nação.

Nesse período, o poder Executivo manteve sob controle político e estratégico a Procuradoria Geral da União (PGR), a Advocacia Geral da União (AGU), o Tribunal de Contas da União (TCU) e outros controles, o que implicou inúmeros arquivamentos e engavetamentos de denúncias públicas e processos de investigação, como os escândalos dos 'anões do orçamento', do salvamento de bancos privados falidos, da internacionalização da telecomunicação, da compra de votos a favor da reeleição no Executivo, da ferrovia Norte-Sul, do metrô de São Paulo, da relação fundos de pensão/fundos de investimento e outros.

\section{Período 2002-2003}

No decorrer desse curto período, o debate social ampliou-se continuamente, iniciando pela inclusão social dos miseráveis, pobres, massa trabalhadora urbana e rural, envolvendo autônomos, classes médias e empresariado desenvolvimentista. O debate eleitoral nucleado no Partido dos Trabalhadores (PT), aderente ao debate social, ampliou para paróquias eclesiais e outras religiões, movimentos de bairros, intelectualidade, artistas etc. $\mathrm{O}$ ideário de uma sociedade mais justa com direitos humanos básicos contemplados por um Estado democratizado e desenvolvimentista encontrou crescente eco nos vários segmentos sociais. $\mathrm{O}$ 'estado de espírito do conjunto da sociedade' resgatava eloquentemente o dos anos 1980, das grandes mobilizações das 'Diretas já', dos debates constitucionais e das reformas estruturais do Estado voltadas para um projeto participativo de nação. Em resumo, era o desafio da construção do Ebes brasileiro nas realidades de $2002 / 2003$, por caminhos, etapas e pactos sociais realistas, nos espaços das contradições da áspera hegemonia da globalização financeira.

O País acompanhava a pendulação política que se processava em vários países da América Latina (Argentina, Bolívia, Chile, Equador, Uruguai, Colômbia, Venezuela), cada um com sua peculiaridade histórica e política, ao seu tempo, rejeitou manifesta regressão social vinda do 'ajuste' da globalização financeira dos anos 1990. Por volta da virada do século, elegeram candidaturas comprometidas com a inclusão social, racial, de gênero, desenvolvimento e independência nacional. Em regra, centraram em medidas de inclusão de resultados rápidos e em alguns mais beneficiados com o boom das commodities (grãos, minerais, petróleo, carne e outras). Nessas circunstâncias, as oligarquias aceitaram espaços adicionais de representações democráticas da sociedade em cargos públicos maiores. 


\section{Período 2003-maio/2017}

Fase 1 - O desafogo: as esperanças e expectativas da sociedade foram positivamente impactadas já no início com o reajuste do salário mínimo acima da inflação, o Bolsa Família para extensa camada antes excluída do mercado de consumo e efetivação e ampliação do Benefício de Prestação Continuada (BPC) criado na Constituição de 1988. O impacto da inclusão estendeu-se rapidamente à reativação do mercado interno produtivo e comercial, chegando aos utensílios domésticos 'linha branca' e construção civil, esta, na sequência, beneficiada com o programa Minha Casa, Minha Vida. Segmentos médios e médio-altos da sociedade, beneficiados indiretamente, tiveram acesso à inusitada expansão de condomínios nas periferias das cidades médias e grandes. Essa grande inclusão social e desenvolvimento do mercado interno, componente típico e inabdicável da construção do Ebes, levou a índices de aprovação governamental jamais atingidos no País: acima de $80 \%$. Historicamente, a perspectiva dessa construção certamente estaria apontando para a ampliação do debate e pactos sociais em função das reformas estruturais do Estado, por etapas pactuadas, voltadas para o projeto de nação já referido nas análises dos períodos anteriores.

Fase 2 - Início de tensão: o inevitável cumprimento das metas fiscais de receitas/despesas com pagamento em dia dos juros e demais serviços da dívida pública seguiu a política macroeconômica do período 1990-2002, de exponencial acumulação do capital financeiro e concentração da riqueza e renda, fez-se acompanhar da ausência de alternativas estruturalmente desenvolvimentistas e distributivistas, com vistas a redes públicas universalistas de qualidade - saúde, educação, transporte coletivo, meio ambiente e outras. O fluxo dos recursos públicos ao sistema financeiro e concentração da renda foi sendo garantido pela continuidade da rígida contenção de gastos federais com as políticas públicas básicas - saúde, educação, transporte coletivo, meio ambiente, outras - acompanhada por elevados subsídios ao mercado nesses setores, com valores muito menores que os necessários para redes públicas universais de qualidade, além do aumento da receita proveniente do boom das commodities.

Apesar da satisfação da sociedade com a inclusão social pelo consumo e ativação do mercado interno, várias e crescentes tensões passaram a surgir nos movimentos sociais com a ausência de redes públicas permanentes e de qualidade para os direitos básicos e efetivo compromisso público com elas. Também no mundo do poder político, os partidos situacionistas coligados e lobbies privatistas tencionavam para estancar ou diminuir os gastos com a inclusão social, mesmo que realizada pelo mercado, a benefício de suas demandas espúrias por recursos públicos. Já ficava visível que das nove diretrizes estratégicas implementadas no período 1990-2002, na prática, apenas a primeira, a sexta e a oitava foram substituídas por diretrizes alinhadas aos direitos sociais e interesse nacional, permanecendo vigentes as demais.

Fase 3 - Sinalização: o 'mensalão'. Os Ministérios estratégicos e Banco Central, referidos no período 1990-2002, emitiram sucessivas sinalizações políticas e de gestão pública, apontando claramente que a etapa de postergação da retomada da formulação democrática e amplo debate do projeto de nação passava ao mero abandono, confirmando-se o projeto de governo e poder com grande inclusão social pelo consumo. Apesar do evidente viés do antiesquerdismo e antipetismo, a crise do 'mensalão' deixou contundente rescaldo de elevados gastos públicos com 'compra' de apoios parlamentares, enriquecimento ilícito em cargos executivos incluindo ministros e dirigentes partidários, alguns anteriormente tidos como exemplares no trato da coisa pública. Mais uma vez na política, especialmente sem a necessária transparência no exercício do poder, os fins, ao justificar os meios, em tempo surpreendentemente curto, transformam os meios em fins. Ainda assim, a inclusão social alcançada pelo consumo e pelo mercado interno manteve 
potencial de esperança e expectativas suficientes para desaguar nas eleições de 2006 e, mais à frente, de 2010.

Fase 4 - A captura de pilares do Estado: por outro lado, a sistematização da triangulação referida anteriormente (financiamento de campanhas eleitorais por grandes empresas, aprovação por maioria parlamentar de projetos do executivo mediante nomeação de indicados para certos cargos e superfaturamento nos contratos públicos das grandes empresas) passou para a fase mais agressiva. Desdobrouse com novos atores acrescentados no seu centro motor: novas grandes empresas e seus bilionários no agronegócio, empreiteiras, extração e refino do petróleo, estaleiros, bancos privados, atores no plano político partidário, marqueteiros com custos estratosféricos para campanhas eleitorais e indução/destruição de imagens na mídia.

A eficiência e eficácia dessa triangulação, com os superfaturamentos consumindo nacos crescentes do orçamento público, acabaram por contribuir pesadamente no desequilíbrio fiscal receita-despesa da União e descontrole dos governos federais. Ainda muito distante do grande ralo: os serviços da dívida pública que levam mais da metade das despesas da União. Contudo, essa triangulação não representa somente o abandono do projeto democrático de nação a favor de projetos de governo e poder, foi além com a captura da estrutura do Estado republicano, centrando no Executivo e Legislativo com extensões pontuais no Judiciário.

Em nome do presidencialismo de coalizão que, nas democracias maduras, são coalizões partidárias excepcionais ou eventuais em torno de objetivos maiores especiais, levando em conta as identidades programáticas dos partidos, no Brasil, a coalizão partidária vem sendo permanente, subvertendo as identidades e programas partidários dos 35 partidos vigentes. Os pilares da República estão quebrados. Estudo da respeitada Tax Justice Network com dados do Banco Mundial, Fundo Monetário Internacional (FMI) e Banco de Compensações
Internacionais revelou que o País ocupava, em 2012, o quarto lugar em depósitos nos paraísos fiscais: US\$ 520 milhões ( $\mathrm{R} \$ 1$ trilhão). A também respeitada Revista Forbes apontou que, em 2013, nossos novos bilionários passaram de 43 para 65 , com as 15 famílias mais ricas concentrando R $\$ 270$ bilhões (5\% do PIB). Os offshores suíços (um terço dos paraísos fiscais do mundo) reconhecem milhares de contas brasileiras usadas na lavagem de dinheiro de propinas geradas na relação grandes empresas-autoridades do Estado, contas que serão abertas em 2019. Hoje nossos seis cidadãos mais ricos retêm riqueza igual à soma dos $50 \%$ mais pobres (mais de 100 milhões). Ademais, legalmente, em 2016, nosso tesouro nacional pagou de juros aos rentistas $R \$ 730$ bilhões (60 bilhões mensais ou 2 bilhões por dia).

Fase 5 - A crise: com todos esses ralos, em 2013, já era indisfarçável o caminho para a crise estrutural: a retração do investimento público e privado na produção e comércio (interno e externo), levando à retração da arrecadação/ receita versus a elevação dos gastos públicos com os serviços da dívida e com a triangulação acima relatada. Para a estabilidade da coligação governamental, esgotavam-se os limites de ampliar os duros cortes que já vinham reprimindo os direitos sociais. Nesse ano, grandes manifestações de rua aparentemente espontâneas eclodiram em várias capitais: trabalhadores precários autônomos e assalariados informais, pobres, provavelmente incluídos no mercado nos últimos anos, maioria jovem, com bandeiras de mais transportes coletivos, educação, saúde e outras.

As reações governamentais, político/partidárias, importante parte da estrutura sindical e da intelectualidade mais avançada, aparentemente subestimaram ou se amedrontaram, talvez perdendo momento histórico de debater com a sociedade o projeto de governo e poder e de voltar seu horizonte para um projeto de sociedade e nação. Esse espaço foi cooptado pelos debates eleitorais de 2014 que cindiram a sociedade ao meio em torno de projetos controversos, ambos afastados do amplo debate 
social de projeto de nação com democratização do Estado e reformas estruturais. Cada um com seu projeto de poder e governo. Nas grandes mobilizações de 2014, 2015 e 2016, mais de 80\% em todas as pesquisas nos dois lados posicionaram-se igualmente contra a corrupção nos governos e a favor da elevação dos gastos públicos com saúde, educação, transporte coletivo, segurança e outros direitos sociais. Em 2015, já no início de campanha pelo impeachment, um número crescente de intelectuais, políticos e lideranças, comprometido com o debate por um projeto de nação, pôs-se em campo, debateu intensamente e apresentou ao debate público, aos partidos e governo, em setembro de 2015, uma bela proposta: 'Por um Brasil justo e democrático: alternativas para o Brasil voltar a crescer. Subsídios para um projeto de desenvolvimento nacional', subscrito por sete entidades e movimentos como o Centro Internacional Celso Furtado, Plataforma Política Social, Fundação Perseu Abramo e outras. É a iniciativa que poderia ter acontecido com determinação pelo menos dois anos antes ou nos debates eleitorais desde 2006.

Fase 6 - A Lava Jato: reação político-institucional. No âmbito dos papéis republicanos dos poderes de Estado, a autonomia do Legislativo para legislar enquanto caixa de ressonância da sociedade e controlar a execução das Leis foi deixando um vácuo desde os anos 1990, incluindo o do controle do Executivo, ao ponto de fragilizar funções essenciais do Estado de Direito e respectivos preceitos constitucionais. A partir de certo ponto, começou a ser parcialmente compensado pelas prerrogativas constitucionais do poder Judiciário e órgãos com funções de controle como o Ministério Público, TCU, Polícia Federal e outros. Esse preenchimento talvez sofreu influências político-partidárias desde o início da operação Lava Jato e outras, mas a evidência que parece predominar é a de 'centrar' no miolo da triangulação que capturou o Estado, isto é, nos partidos que estão no poder, no Executivo e Legislativo antes e após o impeachment, e nas grandes empresas envolvidas na triangulação. Atingiu a aplicação da 'triangulação' em outros países como Peru, Argentina, Equador, Venezuela, Angola, Namíbia, Guiné e Moçambique. Ao que os fatos e análises parecem indicar, o referido preenchimento desse vácuo parece estar chegando ao seu limite, o que exige da sociedade, suas representações e poderes a grandeza e esforço redobrado de reconstrução dos pilares republicanos fraturados do Estado Democrático de Direto. Pressupostamente, sem retorno, saudosismo ou revanchismo em relação a todos os períodos pós-constitucionais implementados pela referida triangulação 'presidencialismo brasileiro de coalizão'. No conjunto das reformas estruturais inadiáveis, emerge então a reforma política e eleitoral, incluindo a refundação do quadro partidário e implementação de carreiras públicas extensivas a todas as funções de direção com exceção dos ministros e presidentes das instituições da administração indireta, sem prejuízo das reformas tributária, previdenciária, econômica, industrial, efetivação das políticas públicas constitucionais dos direitos fundamentais etc.

Fase 7 - Algumas janelas da continuação da luta: analistas apontam que no âmbito da América Latina os países que elegeram governos populares e progressistas na virada do século, em regra, mostraram-se desprovidos de alicerces que somente mudanças estruturais democratizantes podem garantir, ante a aliança do sistema financeiro especulativo (donos do capital) com as oligarquias e a retração do boom das commodities. Apontam também que, entre dezenas de países com grave recessão, o Brasil, apesar das piores taxas mundiais de juros, desigualdade, ensino, mortes no transito, homicídios etc., dispõe de maior capacidade técnica de gerir economia e governo, com economia e recursos bastante diversificados e com instituições empenhadas e em condições de manter uma democracia política com algum grau de civilização, ordem e olhar para o futuro.

Temos reconhecida acumulação histórica de formulações e proposições para ampliação dos debates e sua consistência com vistas aos pactos sociais. Além da importante proposição 
apresentada em setembro de 2015 anteriormente referida, há também o 'Manifesto BrasilNação', de março de 2017, com 172 subscrições originais, conhecido como Bresser-Pereira (PEReIRA, 2017), assim como o 'Plano Popular de Emergência', de maio de 2017, com 76 proposições sistematizadas em 10 itens da Frente Brasil Popular, além de outras que também poderiam ter acontecido com determinação após o mensalão ou após as mobilizações de 2013. Sem descuidar do aqui e agora das mobilizações e pactuações necessárias possíveis, tornou-se mais do que nunca inabdicável e inadiável a construção de objetivos e pactos para médio prazo que venham orientar o que fazer no prazo curto.

Já está insustentável o tensionamento do processo produtivo e da esmagadora maioria da população nas últimas décadas, devido à poderosa sucção da riqueza produzida pelo 'buraco negro' da acumulação financeira especulativa. Além do destino de mais de $50 \%$ do Orçamento Geral da União para os rentistas da dívida pública que retrai o investimento público no desenvolvimento, o investimento privado nas empresas é inibido pelos juros exorbitantes dos empréstimos pelos bancos privados e agências financeiras; e nas empresas maiores, intensificou-se a aplicação dos lucros no mercado financeiro inclusive em títulos da dívida pública, caindo o reinvestimento na empresa. Ora, a esmagadora maioria da sociedade depende direta e exclusivamente do processo produtivo, formal ou informal: o trabalho assalariado e por produção, presencial ou não, autônomo, micro, média e grande empresa etc. São os trabalhadores miseráveis e sobreviventes com renda abaixo de 1 salário mínimo (6,6\% da população), a massa de trabalhadores pobres com renda 1 a 2 salários mínimos (23,2\%), trabalhadores classe média baixa com 2 a 5 salários mínimos (46,2\%), trabalhadores classe média média com 5 a 10 salários mínimos (15\%), totalizando até aqui $91 \%$ da população, aos quais podem ser acrescentados parte dos trabalhadores da classe média alta, por volta de $5 \%$, restando 3 a $4 \%$ de parte da classe média alta e elite que dependem do processo especulativo com descomunal e crescente concentração da renda (FRENTE BRASIL POPULAR, 2017).

Com a globalização vigente, o inusitado salto tecnológico e de produtividade, principalmente para os que dependem do processo produtivo, vem pulverizando e precarizando as relações e processos de trabalho, ampliando as designações de pessoas físicas e jurídicas: autônomos, colaboradores, salário flexível, trabalho polivalente, economia digital, parcerias, trabalho on-line, células de produção, subterceirizados, redes colaborativas etc., com pulverização e potencialização de inúmeras e novas formas de extração da mais valia. Nos donos do grande capital, temos os 1\% da pesquisa de Piketty (2013) que se ampliam a $2-3 \%$ de grandes especuladores incluindo os rentistas de $80 \%$ da nossa dívida pública e agiotas dos empresários produtivos.

Como reconstruir social e politicamente arco majoritário que venha regular e conter a sucção e poder da especulação, a favor de pactuações desenvolvimentistas? Com distributivismo orientado pelos direitos sociais de cidadania entre todos os estratos que dependem do processo produtivo de bens e serviços incluindo ciência e tecnologia? Regulando e contendo fortemente - pela sociedade organizada e por um Estado efetivamente democrático - inclusive tornando o reinvestimento na produção e nos direitos sociais, claramente mais vantajoso do que na especulação?

\section{Três destaques oportunos}

Ao finalizar, destacamos a importância de serem resgatados e atualizados os debates e mobilizações dos anos 1980 em torno da democratização do Estado e decorrentes reformas estruturais desse Estado. Está em pauta a reestruturação de procedimentos que garantam efetiva representação democrática da sociedade nos poderes Legislativo e Executivo com efetiva transparência no controle dos atos executivos e legislativos 
por meio das reformas política e eleitoral. As informações comprovadoras da captura do Estado pelo grande capital, que vem sendo reveladas à opinião pública até o momento, já começam a alimentar o debate de reformas que barrem a continuidade dessa captura. Hoje essa captura envolve a maioria dos mais altos escalões dos poderes Executivo e Legislativo, desviando enormes nacos do orçamento público, cujo dono é a população. Convimos que as demais reformas estruturais, como a previdenciária, tributária, trabalhista, econômico-financeira e outras, atenderão os direitos sociais e o desenvolvimento nacional, paralelamente a efetivação de real representação da sociedade nos referidos poderes.

Em um segundo destaque, convimos que os movimentos sociais e políticos pelos direitos sociais e desenvolvimento no País, pontificados nos anos 1980, nasceram e se desenvolveram guiados por valores de direitos humanos universais, desde o início assumindo e cultivando valores de um sentido comum para a vida, de alteridade e solidariedade. Linera (2003, NÃO PAGINADO) estende esse

[...] sentido comum ao bem comum: água, ar, natureza, trabalho, transporte, educação, saúde, outros. E a política, além da questão da correlação de forças e das mobilizações, deve ser fundamentalmente a construção e encontro de um sentido comum, de uma ideia compartilhada de convencimento e articulação. Mais ainda: que seja voltada para medidas objetivas e concretas sob a lógica dos recursos públicos e comuns serem integralmente alocados para a realização dos bens comuns, e não para a acumulação dos bens privados e bancários.

Aparentemente, líderes e dirigentes dos movimentos sociais e políticos acima referidos, partidarizados ou não, arrefeceram ao longo dos anos, em diferentes graus e formatos, o cultivo e a prática desses valores, delegando esse compromisso e prática aos projetos de governo e poder nos períodos de 1990-2002 e de 2003 até o momento. Tornase imprescindível o retorno de dedicação maior e permanente ao cultivo e prática desses valores, com explicitação em todos os momentos das militâncias, sem o sentimento de ingenuidade, irrealismo e perda de tempo.

Terceiro destaque: na experiência do exercício de poder na estrutura do Estado, há um ângulo dessa estrutura (Executivo/ Legislativo/Judiciário), que é a acumulação de milhares de órgãos de todos os níveis hierárquicos, com objetivos e funções diversificados superpostos ou não e com diferentes autonomias. Cada um desses órgãos portando acumulação de regramentos burocráticos, e todos eles criados e adaptados cumulativamente desde o Estado monárquico imperial. No seu conjunto, realizam a ordem político-administrativa e hegemonia vigentes. Um 'cipoal' aparentemente inexpugnável cuja lógica organizacional acumulada responde secularmente aos interesses, objetivos e estratégias dos proprietários dos meios de produção e dos bancos e agencias financeiras, os 'donos do PIB'. Uma das funções históricas desse 'cipoal' é a de realizar permanentemente o jargão 'para os amigos tudo e para os inimigos a Lei'. Nos estamentos superiores desse complexo burocrático, principalmente no poder Executivo, estão os tecnocratas das licitações, concessões e compras públicas assim como os ordenadores de despesas, todos integrantes de órgãos mais consolidados ou perenes com responsabilidade maior na manutenção e função da estrutura que alguns nomeiam 'aparelhos de Estado'.

Outra função histórica desse 'cipoal' vem sendo a de cooptar novos técnicos e dirigentes que a ele chegam, inclusive por meio de sutilezas de seduções e deslumbramentos no exercício do poder, no novo status do (da) recém-empossado (a), até a racionalização de que os fins justificam os meios. Nessa função histórica, os aparelhos de Estado 'aparelham' técnico-burocratas e dirigentes, a nosso ver, com eficiência bem maior, sob lógica similar 
à de partidos que 'aparelham' órgãos públicos. Vemos aqui outro grande desafio que pode ser equacionado somente pela efetiva democratização do Estado, com o conjunto da sociedade debatendo seu projeto de nação e consequentes e inadiáveis reformas estruturais, não mais projetos de governo e poder.

\section{A grande crise da política pública da saúde enquanto consequência}

Em 1974, aos 29 anos da sua criação oficial, o Sistema Nacional de Saúde inglês já era modelo para outros países, inclusive para o Brasil, que avançava os debates da reforma sanitária com a criação do Centro Brasileiro de Estudos de Saúde (Cebes). Na sua criação oficial, com base nos acertos do sistema inglês e outros avançados sistemas públicos de saúde, o Sistema Único de Saúde (SUS) foi contemplado pela Constituição Federal de 1988 com indicações e consignações para financiamento suficiente e diretrizes claras para a organização e gestão com universalidade, integralidade e equidade. Em 2017, também aos 29 anos da sua criação oficial, o SUS permanece com o per capita do financiamento público, 5 a 6 vezes menor que a média dos 15 países com melhores sistemas públicos de saúde, países que destinam em média perto de $8 \%$ do PIB em recursos públicos para saúde quando nós oscilamos entre 3,7 e 4\%. Em decorrência, o desinvestimento público nos serviços próprios do SUS leva à compra de serviços privados complementares de $65 \%$ das hospitalizações e de mais de $90 \%$ dos procedimentos diagnósticos e terapêuticos, com incontroláveis distorções na aplicação das diretrizes do SUS, o que não ocorre nos 15 referidos países. Da mesma maneira a terceirização a entidades privadas fornecedoras de recursos humanos com contratos precarizados, de $65 \%$ dos profissionais do SUS, o que também não ocorre naqueles países, nem tampouco as polpudas subvenções públicas ao mercado de planos e seguros privados de saúde, equivalentes a mais de $150 \%$ do lucro líquido por eles declarado. Como se não bastasse, foram efetivados polpudos empréstimos fortemente subsidiados pelo Banco Nacional de Desenvolvimento Econômico e Social (BNDES) e outros para empresas de planos privados construírem seus hospitais próprios e para hospitais privados sofisticados de grande porte dobrarem sua capacidade instalada, além da abertura da nossa rede hospitalar ao capital estrangeiro.

Essas e outras investidas truculentas sobre o SUS constitucional vem permeando por igual os seus 29 anos uma cobertura de $75 \%$ da população que só usa o SUS (não compradora de planos privados), com financiamento per capita 5 a 6 vezes menor do que o dos $25 \%$ que compram e utilizam os planos privados além de utilizarem o SUS, inclusive com ações judiciais. O fio condutor dessa construção de outro sistema que não o SUS tem origem nos Ministérios estratégicos de Estado: Fazenda, Casa Civil e Planejamento-Orçamento-Gestão, 'benzidos' pelo Banco Central e explicitado em 1995 no Relatório do Banco Mundial (Bird) (RIZZOTTO, 2000, 2006), o que manteve a gestão do Ministério da Saúde sob constrangimento permanente, levando ao pedido de demissão por dois respeitados Ministros nos anos 1990. Na prática, nosso sistema público de saúde vem cumprindo papel determinado pela estratégia global neoliberal de outro modelo batizado de 'Cobertura Universal de Saúde', arranjo público-privado que afronta os melhores sistemas públicos de saúde no mundo e as nossas diretrizes constitucionais. Ainda assim, o SUS foi a política pública que mais avançou, com militância mais aguerrida e politizada desde o combate à ditadura e debates constitucionais. 'Tomou porre' de vitória com a Constituição achando que aplicá-la seria menos desafiante que debatê-la e aprová-la. Mesmo apanhando, o SUS 
estendeu a cobertura dos serviços públicos integrais à metade mais pobre da população antes descoberta. Mais ainda: a militância de milhares de trabalhadores de saúde, gestores e conselheiros de saúde, acadêmicos (docentes, alunos e pesquisadores) etc. estruturou e implementou com consistência muitas 'ilhas' ou 'nichos' de excelência ao nível dos melhores sistemas de saúde do mundo, pelo menos em nove áreas: vigilância em saúde, atenção básica ou primária/ saúde de família, saúde mental (Centros de Atenção Psicossocial - Caps), saúde do trabalhador (Centros de Referência em Saúde do Trabalhador - Cerest), urgência/ emergência (Serviço de Atendimento Móvel de Urgência Samu), DST/Aids (Doenças Sexualmente Transmissíveis/Síndrome da Imunodeficiência Adquirida), sangue e hemoderivados (Centro de Hematologia e

\section{Referências}

BRESSER-PEREIRA, L. C. et al. Manifesto do Projeto Brasil. 2017. Disponível em: <http://www.nocaute.blog. br/brasil/manifesto-do-projeto-brasil-nacao.html>. Acesso em: 10 maio 2017.

FRENTE BRASIL POPULAR. Plano Popular de Emergência. 2017. Disponível em: <http://agenciabrasil. ebc.com.br/sites/_agenciabrasil2013/files/files/Plano_ Popular_de_Emergencia.pdf $>$. Acesso em: 10 maio 2017.

LINERA, A. G. As esquerdas da Europa e do mundo. 2013. Disponível em: <http://www.cartamaior.com. br/?/Editoria/Internacional/alvaro-Garcia-Linera-as-esquerdas-da-Europa-e-do-mundo/6/29876>. Acesso
Hemoterapia - Hemocentro), transplante de órgãos e tecidos e no âmbito da gestão, pronunciado avanço nas articulações e instâncias de pactuação interfederativa e controle social. Esses avanços, longe de constituírem a regra, encontram-se cingidos a exceções no território nacional, mas com massa crítica bastante consistente de competência acumulada em atenção integral à saúde e gestão de processos de trabalho mais adequados. Hoje, verdadeiras ilhas de avanços possíveis e de resistência ao desmanche, devem ser assumidos como insubstituível patamar para futura retomada do rumo inicial da construção do SUS. Minha maior admiração e reverência a essa militância, que como cidadãos e cidadãs estão desafiados a participarem com o mesmo empenho na militância cidadã geral abordada nos períodos históricos anteriores, que fazem do SUS uma das consequências. em: 11 maio 2017. Não paginado.

PIKETTY, T. O Capital no Século 21. Rio de Janeiro: Intrínseca, 2013.

RIZZOTTO, M. L. F. O Banco Mundial e as políticas de saúde no Brasil nos anos 90: um projeto de desmonte do SUS. 2000. 266 f. Tese (Doutorado em Saúde Coletiva) - Universidade Estadual de Campinas, 2000. . As propostas do Banco Mundial para as reformas do setor saúde no Brasil nos anos 90. Saúde em Debate, Rio de Janeiro, v. 29, n. 70, p. 140-147, 2006. 